\title{
Ein geschickter Mann
}

_ Mein Opa Burkhardt war ein geschickter Mann. Das erzählen meine Oma, meine Mutter und alle, die ihn kannten. Aus abgebrannten Streichhölzern baute er Nachttischlämpchen, die aussahen wie kleine Windmühlen. Und er drechselte Kerzenständer so hoch wie ein Arm.

_ Leider starb er mit 60 Jahren nach seinem zweiten Schlaganfall. Meine Erinnerungen an ihn sind dürftig. Aber ich sehe ihn vor mir, wie er in der Küche sitzt, mich mit seinen tiefen Lachfalten angrinst und sagt: „Na, du kleine Marke.“ Da war ich vier oder fünf Jahre alt.

_ Seinen ersten Schlaganfall erlitt Opa Burkhardt 1986. Für ihn war es furchtbar, denn er verlor sein feinmotorisches Geschick. Den obersten Knopf vom Hemd bekam er nicht mehr zu, mit Mühe konnte er noch schreiben. Das Arbeiten mit Holz gab er nahezu auf. Mein Opa war wütend. Statt einer gezielten Therapie erhielt er von seinen Ärzten einen kleinen Knautschball. Damit sollte er seine Handkraft trainieren.

_ Heutzutage reicht ein kleiner Ball als Rehamaßnahme nicht mehr aus. Ich bin froh, dass sich die Ergotherapie hier etablieren konnte. Mein Opa, der immer viel handwerklich machte, hätte sehr von Ergotherapie profitiert. Er hätte sich wieder ordentlich anziehen und wieder mit Holz werkeln können.

_ Dass sich Ergotherapie sogar noch Jahre nach dem Schlaganfall lohnt, berichtet ein Klient im Artikel „Leben mit Hemiplegie“ auf S. 24.

_ Die Ergotherapie ist heute selbstverständlicher Teil der Neurorehabilitation und steht vor der Herausforderung, zunehmend Wirksamkeitsnachweise zu erbringen. Passend dazu stellen wir Ihnen den Artikel von Björn Stritzinger vor (๑ S. 35). Der Ergotherapeut verbannte Bobath und Co. aus seinem Repertoire und setzt nun evidenzbasierte, robotergestützte Verfahren für Menschen mit Hemiplegie ein. Damit ist er glücklicher und erfolgreicher als zuvor.

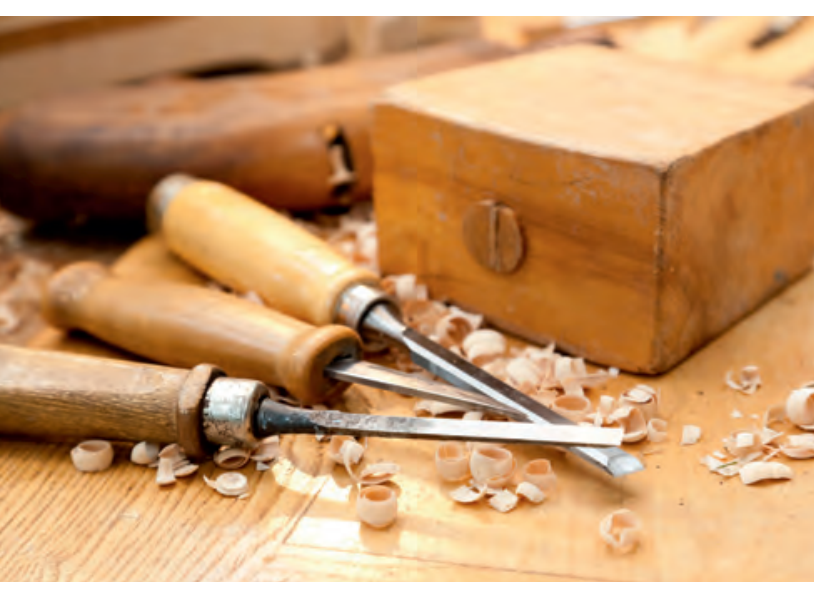

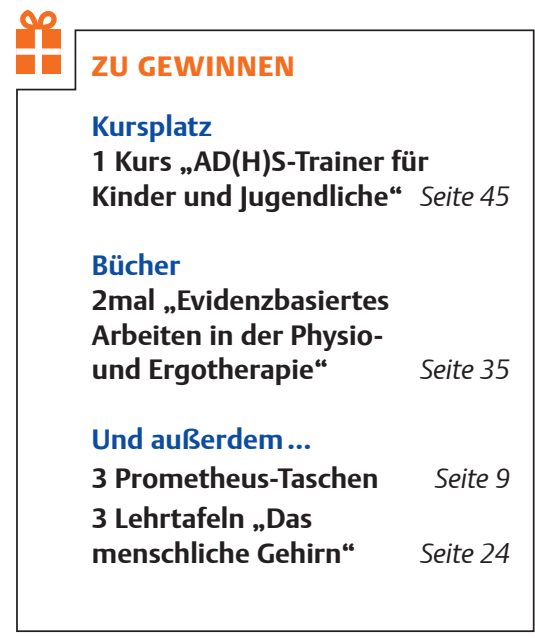

Viele Grüße, Ihre

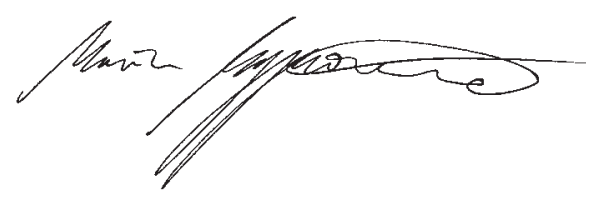

